\title{
PAPEL DO FARMACÊUTICO DURANTE A PANDEMIA DA COVID-ı9
}

\author{
Fabiana dos Santos Pinto ${ }^{1}$ \\ Guilherme Corrêa Polkowski² \\ Israel Rocha Lima ${ }^{3}$ \\ Anny Carolinny Tigre Almeida Chaves ${ }^{4}$
}

RESUMO: A Organização Mundial da Saúde (OMS) decretou uma crise mundial na saúde pública e privada, mediante o surto do vírus SAR-CoV2. Sendo assim, a propagação do vírus inicialmente ocorreu na China, na província de Hubei, com 58,5 milhões de habitantes, e espalhou-se para os outros países (OMS, 2020). Ante exposto, o farmacêutico possui uma habilidade de identificação de possíveis problemas, que podem ser solucionados em estudos mais específicos na área da saúde de uma população. Dentre a problemáticas, uma das temáticas recorrentes, a automedicação, definida enquanto uma perspectiva de autocuidado, porém, quando o uso é exagerado, há um ato prejudicial, podendo ter consequências, como efeito indesejado, enfermidades e o mascaramento de doença evolutiva. Sendo assim, o trabalho teve como objetivo apresentar o papel do farmacêutico perante a pandemia da Covid-19, demonstrando a sua importância diante da descoberta de tratamentos eficazes para a patologia em questão e da atenção farmacêutica perante os mais diversos problemas relacionados a medicamentos e as possíveis prevenções que tenham sido publicados na literatura no contexto da pandemia da Covid-19.

Palavras- chave: Atuação profissional. COVID- 19. Farmacêutico.

\section{INTRODUÇÃO}

Em fevereiro de 2020, a Organização Mundial da Saúde (OMS) decretou uma crise mundial na saúde pública e privada, mediante o surto do vírus SAR-CoV2, o qual afetou todo o esquema socioeconômico. A propagação do vírus inicialmente ocorreu na China, na província de Hubei, com 58,5 milhões de habitantes, e espalhou-se para os outros países (OMS, 2020).

Acrescentando-se também que a pandemia da Covid-ı ocasionou uma crise mundial, afetando primordialmente a economia e a educação, utilizando-se de uma nova metodologia para se adaptar a esse momento e tentar reduzir os impactos causados por essa

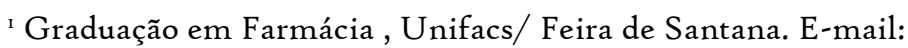

${ }^{2}$ Graduação em Farmácia, Unifacs/Feira de Santana

${ }^{3}$ Graduação em Farmácia , Unifacs/Feira de Santana

${ }_{4}$ Doutora em Farmácia- UESF.
} 
doença, e a saúde. Nesse sentido, o farmacêutico possui uma habilidade de identificação de possíveis problemas, que podem ser solucionados em estudos mais específicos na área da saúde de uma população, com isso introduzir prováveis abordagens terapêuticas e de prevenção contra a Covid-ı9 podem especificar a participação do farmacêutico nesse cenário (FERREIRA et al., 2020).

Um assunto muito debatido pelos farmacêuticos e pesquisadores é a automedicação, que de acordo com a OMS constitui a seleção e o uso irracional de medicamentos, incluindo medicamentos isentos de prescrições médicas, para tratar sintomas leves e moderados. Essa prática não se enquadra só no contexto brasileiro, mas há também uma inquietação mundial, pois, a tentativa de autocuidado afeta inúmeros países (MELO et al., 2020).

Em outras palavras a automedicação é perspectiva de autocuidado, porém, quando o uso é exagerado, há um ato prejudicial, podendo ter consequências, como efeito indesejado, enfermidades e o mascaramento de doença evolutiva (DUARTE et al., 2020).

Contudo, a atenção farmacêutica, área exclusiva do profissional farmacêutico, estabelece várias atividades contínuas e integradas para o uso racional de medicamentos, para a proteção e a restauração da saúde do paciente. Diante da pandemia da Covid-ı9, vale ressaltar à autoridade e domínio técnico que o profissional tende a ter por meio dos seus conhecimentos e dessa maneira a redução das intoxicações, interações medicamentos e óbitos por utilização incorreta dos medicamentos (TRITANY et al., 2020).

Além disso, o farmacêutico exerce um papel extremamente importante no controle da transmissão da covid-19 e na atenção básica para a população durante a pandemia, principalmente na saúde física e mental, é imprescindível que o profissional farmacêutico abranja o cuidado com a saúde metal dos pacientes, consolidada a partir do distanciamento social, reduzindo os impactos causados pela ansiedade, depressão e o luto dos familiares (REBRAM, 2020).

Assim, o presente trabalho tem como objetivo apresentar o papel do farmacêutico perante a pandemia da Covid-ı9, demonstrando a sua importância diante da descoberta de tratamentos eficazes para a patologia em questão e da atenção farmacêutica perante os mais diversos problemas relacionados a medicamentos e as possíveis prevenções que tenham sido publicados na literatura no contexto da pandemia da Covid-ı. 


\section{METODOLOGIA}

O presente trabalho realizado trata-se de uma pesquisa qualitativa, em que sua abordagem é explicar o porquê de certas ocorrências, demonstrando uma profundidade das relações, fenômenos e processos, além de possuir uma preocupação com a qualidade dos dados obtidos sem utilizar de variáveis para a sua composição, ou seja, neste modo de pesquisa dispõe com objetivo explicar os motivos e os comportamentos dos fenômenos (MINAYO,2004).

Esta análise foi realizada em artigos científicos documentais, através de uma revisão de literatura narrativa, onde neste tipo de estudo, são analisadas outras produções bibliográficas com o objetivo de apresentar relações entre pesquisas e demonstrar novas ideias sobre uma determinada área de conhecimento (ROMANOWSKI;VOSGERAU.,2014). Sendo utilizado como base de dados para a obtenção destes artigos científicos a plataforma Science Direct.

Para compor o campo das palavras chaves os pesquisadores decidiram utilizar as seguintes palavras: Assistência Farmacêutica (Pharmaceutical care em inglês ou Cuidado farmacêutico em espanhol) e utilizando como operadores booleanos a sigla AND, tendo como significado em português a conjunção "e".

Os critérios de inclusão utilizados foram artigos pertencentes a plataforma citada anteriormente, artigos publicados em inglês, português e espanhol, publicados entre os anos de 2020 e 2021,e que fossem da área de interesse da farmacologia, toxicologia e ciências farmacêuticas.

Foram utilizados como critério de exclusão do trabalho: artigos com período de publicação anterior ao ano de 2020, artigos que fossem pertencentes a outras áreas de pesquisa não ser da área de interesse para este trabalho e que não fossem publicados em outro idioma, a não ser os escolhidos pelos pesquisadores.

\section{RESULTADOS E DISCUSSÃO}

Foram identificados através da base de dados Science Direct, plataforma escolhida por apresentar uma quantidade superior de artigos na área de interesse referente as demais, 4.oro artigos com as palavras chaves definidas para compor o presente artigo. Após escolher os anos de interesse para tal pesquisa, tal número teve um decréscimo para 3.994 artigos, 
sendo apenas 650 artigos na área definida. Depois de ter definido a área de interesse para a pesquisa, foi definido que só seriam utilizados artigos de pesquisa para a obtenção dos dados, tendo uma redução para 245 artigos. Posteriormente, ao analisar títulos e resumos dos artigos, que foram utilizados para compor a pesquisa 26 artigos (figura I).

Os artigos incluídos nessa pesquisa trataram do consumo de medicamentos em meio a pandemia e o uso irracional de medicamentos, os cuidados farmacêuticos frente a CovidI9 e a importância do profissional farmacêutico em diversas áreas que sua profissão abrange como (drogarias, farmácias, no âmbito hospitalar e em Home Care). Dessa forma, observase o papel essencial do profissional farmacêutico durante esse período, na prestação da assistência farmacêutica, de forma a orientar e informar melhor a população sobre o uso adequado dos medicamentos e sobre os efeitos indesejáveis causados pela automedicação, evitando, assim, agravos à saúde e proporcionando maior cuidado em todos os setores da saúde.

Figura I - Fluxogramas de Prospecção

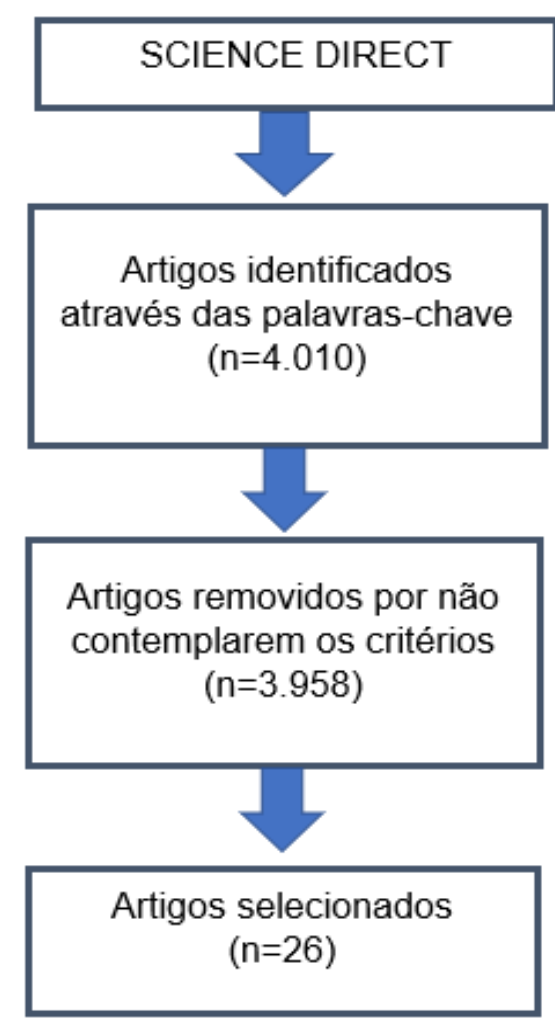

Fonte: Próprio Autor 


\section{I A IMPORTÂNCIA DA ASSISTÊNCIA FARMACÊUTICA EM UMA PANDEMIA}

A Assistência Farmacêutica durante a pandemia da Covid-ı́ é de extrema importância, uma vez que o farmacêutico exerce papel fundamental no controle da transmissão da doença e na atenção às necessidades da população, de forma a promover o uso racional de medicamentos durante a pandemia. (CFF, 2020)

Contudo, só é possível uma Assistência farmacêutica por meio do profissional habilitado para essa função. E, é nesse sentido que o profissional farmacêutico assume a responsabilidade e o protagonismo na implementação de estratégias para promoção do uso racional de medicamentos, em virtude das consequências danosas do seu uso inadequado. Além disso, o trabalho do farmacêutico é componente fundamental da qualidade da Assistência Farmacêutica que, por sua vez, tem implicações diretas na eficiência dos sistemas de saúde e no sucesso da terapia medicamentosa (ROCHA, GIOTTO., 2020).

No entanto, a partir de dezembro de 2019, o cenário passou por uma imensa transformação no âmbito da saúde mundial. $\mathrm{Na}$ China, foram identificados casos de uma nova doença respiratória aguda provocada por um novo coronavírus (2019-nCoV), que foi denominada como Covid-19 (coronavirus disease 2019). Em um primeiro momento ela se tornou uma epidemia, mas, em março de 2020, a Organização Mundial da Saúde (OMS) declarou que a Covid-rg já havia se tornado uma pandemia global (JIANG et al., 2020).

Desde então, os profissionais farmacêuticos de todo o mundo vêm buscando formas de responder, agir e se adaptar para manter a continuidade das atividades relacionadas a Assistência farmacêutica e a qualidade dos serviços (SILVA et al., 2020).

Devido ao agravamento rápido da doença, a situação foi dada como crítica, e os profissionais da saúde da linha de frente ficaram diretamente envolvidos no cuidado, diagnóstico e tratamento dos pacientes com Covid-19. Em epidemias de doenças contagiosas, os profissionais de saúde tendem a correr um risco maior de contaminação do que a população em geral. Nessa circunstância, o farmacêutico exerce papel importante, pois deve agir no controle da transmissão da doença e na atenção às necessidades da comunidade durante a crise, disseminando informações sobre a doença, além de monitorar reações relacionadas ao uso de medicamentos (CAGNAZZO; CHIARIANDRÉO, 2020). 
Frente à pandemia da Covid-ı, o farmacêutico teve de organizar suas atividades e ações de forma colaborativa, dando suporte às unidades de urgência e emergência, evitando a sobrecarga e colapso do sistema de saúde. As farmácias, geralmente, representam o primeiro acesso ao cuidado e à saúde e, nesse período, isso contribui com a redução do risco de contaminação dos pacientes que buscam serviço ou por orientações, além de manter atenção farmacêutica ativa no controle e monitoramento dos registros manuais de saúde, principalmente nos grupos de risco $(\mathrm{CFF}, 2020)$

\section{I PROBLEMAS RELACIONADOS A MEDICAMENTOS DURANTE A PANDEMIA DA COVID-19}

Como a doença provocada pelo Sars-Cov-2 não possui um tratamento eficaz, as maiores agências relacionados a Saúde começaram a adotar terapêuticas de reposicionamento de medicamentos com embasamento de testes in vitro. A Food and Drug Administration (FDA) e a Organização Mundial da Saúde (OMS), sugeriram grupos de medicamentos reutilizáveis, tais como antivirais (remdesivir), anti-hipertensivos, antihelmínticos, antimicrobianos e outros (SMAIL et al., 2020).

Brito et al. (2020) justificam tais usos dessas classes medicamentosas, por possuírem grandes efeitos terapêuticos benéficos contra a Covid-ı e por serem grupos medicamentosos mais pesquisados e indicados por médicos e profissionais especializados (BRITO et al., 2020). O grande problema relacionado a distribuição de notícias relacionadas a esses medicamentos de reposicionamento é o uso exacerbado desses medicamentos sem uma devida prescrição correta, ocasionando um aumento na automedicação e posteriormente em problemas relacionados ao uso indevido desses medicamentos (FALAVIGNA et al., 2020).

A automedicação é uma prática realizada mundialmente e que preocupa as maiores organizações de saúde por provocarem efeitos colaterais graves, principalmente pelo uso concomitante de medicamentos sem analisarem as interações medicamentosas relacionadas a esse uso irracional. Na pandemia da Covid-ıg, uma doença de fácil contaminação e de um esgotamento perante os profissionais de saúde, muitos pacientes acabaram por não conseguir uma consulta com um profissional especializado, e se submeteram a automedicação por terem medo de serem contaminados pelo vírus ou para que a doença não agrave (GOMES et al., 2020). 
Com a eclosão da pandemia da Covid-19, os pesquisadores e cientistas buscaram estratégias para um tratamento que fosse eficaz para tal patologia, tais como medicamentos reaproveitados e vacinas. Um exemplo desses medicamentos são as glicirrizina, pertencentes ao grupo das saponinas, que demonstraram grande eficácia para a Covid-19 (SHARMA et al., 202I). Tais medicamentos como as glicirrizina, são considerados eficazes para a Covid por serem medicamentos com características farmacológicas já estudadas para outras patologias e por apresentarem testes in vitro eficazes para ela (SILVA NETO et al., 2020).

Os antivirais são os medicamentos mais utilizados para o tratamento da covid, pois esse grupo inibe e bloqueia a replicação do vírus, causando uma interferência na fixação dos vírus nas células. A principal preocupação de pesquisadores ao procurar um medicamento com eficácia para a covid-ı́ é que o mesmo tenha efeito farmacológico positivo contra o vírus, sem prejudicar o paciente e como resposta do fármaco, um impedimento do vírus chegar ao seu hospedeiro (SHARMA et al., 202I).

Porém qualquer medicamento Antiviral atualmente não apresenta provas concretas de eficácia para a Covid-ı9, entretanto tais medicamentos estão sendo utilizados como cuidados de suporte para oferecer aos pacientes um maior alívio dos sintomas e das complicações provocadas por esta patologia. Farmacêuticos e cientistas continuam pesquisando medicamentos mais eficazes e seguros para tal doença (MA QINHAI et al., 2020).

Os Anti-inflamatórios não esteroides (AINEs), por exemplo, são utilizados durante a pandemia por serem eficazes em sintomas comuns na covid-19, tais como febre e dor, porém como esse grupo faz parte dos Medicamentos Livres de Prescrição (MIPs) houve uma grande procura por eles em todas as drogarias (CFF, 2020). Entretanto, diversos pesquisadores tais com Michael Day (2020) recomendam que os pacientes portadores da Covid-ı9 não utilizem Ibuprofeno para o tratamento destes sintomas, pois ele pode provocar um agravamento no quadro clínico e problemas de saúde subjacentes (SMAIL et al., 2020).

A Hidroxicloroquina, medicamento antimalárico utilizado como medicamento de reposição para a covid-I9 (DE MARGERIE et al., 202I) apresentam grandes efeitos colaterais 
quando utilizado concomitantemente com outros medicamentos como, por exemplo, com a Azitromicina, e por apresentarem uma dosagem acima do recomendado. $O$ uso da Hidroxicloroquina com a Azitromicina, medicamento pertencente ao grupo de antibióticos, podem causar arritmia ventricular, falência hepática e outros (IMOTO et al, 2020).

Outro medicamento utilizado no famoso "Kit Covid" é a ivermectina, um medicamento antiparasitário utilizado para tratamento de humanos e veterinário, usada para o tratamento de doenças parasitarias (MARRA et al, 2020). Apesar de apresentar estudos in vitro para a suposta eficácia desse medicamento perante a Covid-I9, o uso indiscriminado e abusivo deste medicamento pode causar hepatite medicamentosa (HOSPITAL ANCHIETA, 202I).

O Remdesivir, fármaco antiviral sugerido para o tratamento da covid-ı́, pode ser defendido por causa do seu mecanismo de ação que age diretamente na síntese do seu RNA polimerase, ao qual ocasiona um retardo na terminação da cadeia viral e acaba por diminuir a sua produção de RNA (CARESTIATO et al., 2020). A aplicação desse medicamento só deve ser feita em ambiente Hospitalar por se tratar de um medicamento injetável e os efeitos

adversos demonstrados durante pesquisas desse medicamento são náuseas, dores nas extremidades, constipação, diarreia e outros (FERNANDES et al, 202I).

Diante de tanta informação ofertada sobre os medicamentos, se torna necessário sempre, que antes de tomar qualquer medicamento o paciente passe antes por um médico ou farmacêutico para que seja realizado a melhor terapêutica a fim de diminuir os efeitos adversos que o uso de diferentes medicamentos possa causar (BEZERRA et al, 202I). Nos Estados Unidos e na Nigéria foram registrados dados sobre indivíduos que se automedicaram com cloroquina e infelizmente acabaram falecendo de envenenamento (SADIO et al, 2020).

\section{I PAPEL DO FARMACEUTICO PERANTE AS TERAPIAS RECOMENDADAS PARA O TRATAMENTO COVID-19;}

A pandemia da Covid-ı9, apresentou uma urgência no aparecimento de terapias emergentes que apresentassem resultados positivos e com um período resposta para os pacientes contaminados. Com escassez de tempo para pesquisas e descobertas de 
terapêuticas destinadas a Covid-ı9, foram utilizados reposicionamento de fármacos com embasamento em ensaios in vitro, e terapias já conhecidas com o intuito de proporcionar o paciente a cura e meios de prevenção. (DUARTE et al, 2020).

Muitos profissionais da saúde atuaram frente a pandemia da Covid-ı9, dentre eles, o farmacêutico, que teve um papel importante no fornecimento de insumos de medicamentos e nas pesquisas relacionadas as possíveis terapias eficazes para a patologia em questão, tendo como base uma farmacoterapia racional que evitassem possíveis complicações nos quadros clínicos dos pacientes (PEREIRA et al., 2020). Diversas terapias foram utilizadas para o tratamento da Covid-I9, tais como Imunoterapia, princípios da medicina chinesa, a acupuntura, e outras terapias com o objetivo central de oferecer maior comodidade para os pacientes infectados (DE-CARLO et al, 2020).

A Acupuntura é um conjunto de conhecimentos teórico-empíricos da medicina chinesa tradicional que visa a terapia e a cura de doenças, que tradicionalmente são realizadas através de aplicações de pequenas agulhas e de moxas ,entretanto, podendo ter outras técnicas. As recentes pesquisas cientificas tem contribuído para uma maior compreensão da Acupuntura (WEN, 2020).

Estudos apontam o aumento de problemas relacionados a saúde mental, como estresses, ansiedade, e insônia durante a pandemia da Covid-ı́ e a medicina chinesa contribui com a melhoria do paciente durante o surgimento de alterações físicas e mentais, sendo que o profissional farmacêutico atua com os serviços trazendo benefícios através da auriculoterapia (TRIGUEIRO et al, 2020).

O sistema respiratório fornece oxigênio e promove a eliminação do dióxido de carbono para a manutenção dos tecidos e das reações metabólicas, onde o vírus da SARSCoV-2 acomete e causa sintomas. Apesar de não ter um tratamento totalmente eficaz para a doença, alguns estudos identificaram que os fitoterápicos podem apresentar um potencial para tratar ou aliviar sintomas da Covid-ı9, sendo assim considerados como terapêutica eficaz para a Covid-ı9 (HADDAD;SHARMA, 2020).

As recomendações dos fitoterápicos variam entre anti-inflamatório, broncodilatador, imunoestimulante e imunomoduladora que atuam nas doenças respiratória e inflamações, 
apesar da atuação ser mais lenta que os antibióticos sintéticos, apresentam menor potencial de reações adversas, além de minimizar e reduzir as cepas e micro-organismos resistentes, sendo assim são recomendados para diversas séries de síndromes clínicas hiperinflamatórias, tais como a linfohistiocitose hemofagocítica (LHH) (RIPHAGEN et.al., 2020)

\section{CONCLUSÃO}

A assistência farmacêutica durante a pandemia demonstrou uma importância perante a sociedade e aos profissionais da saúde, por ser uma área farmacêutica responsável por minimizar os efeitos colaterais dos problemas relacionados aos medicamentos (PRMs). Cabe ao profissional farmacêutico atuar de forma expressiva em relação a assistência farmacêutica tendo em vista a melhoria do bem-estar da sociedade. Para tanto, deve-se capacitar os profissionais de saúde, disponibilizando para os mesmos informações sobre os danos à saúde pelos PRMs. Desse modo, a população entenderá realmente a importância do farmacêutico inserido na segurança a saúde e o bem-estar.

Em virtude dos fatos mencionados no presente trabalho, o farmacêutico está atuando

na linha de frente a essa pandemia e têm se tornado um profissional essencial, uma vez, que possui total respaldo para interagir com as equipes de saúde, discutindo suas experiências a respeito dos medicamentos, doses, efeitos adversos, interações medicamentosas, dando suporte a outros profissionais da saúde e orientando pacientes com atenção farmacêutica.

\section{REFERÊNCIAS}

ADAMS, J. G.; WALLS, R. M. Supporting the Health Care Workforce During the COVID-i9 Global Epidemic. JAMA, [s.1.]. v. 323, n. 15, p. 1439, 12 mar. 2020.

BEZERRA, Vitor de L; ANJOS, Thomás B; SOUZA, Lilian E. S; et al. SARS-CoV-2 como agente causador da COVID-ı: Epidemiologia, características genéticas, manifestações clínicas, diagnóstico e possíveis tratamentos. Braz. J. Hea. Rev., Curitiba, v. 3, n. 4, p. 84528467 jul./ago. 2020. Doi: 10.34II9/bjhrv3n4-097;

BRASIL. Ministério da Saúde. Secretaria de Ciência, Tecnologia e Insumos Estratégicos. Departamento de Assistência Farmacêutica e Insumos Estratégicos. Formulário Terapêutico Nacional 2oro. Rename 2010. 2. ed. Série B. Textos Básicos de Saúde. Brasília: Ministério da Saúde, 2010. I135 p. 
BRITO, Júlio César Moreira et al. Uso irracional de medicamentos e plantas medicinais contra a COVID-i9 (SARS-CoV-2): Um problema emergente. Brazilian Journal of Health and Pharmacy, v. 2, n. 3, p. 37-53, 2020.

BRUN-BUISSON, C. et al. Corticosteróides precoces na pneumonia por influenza A / $\mathrm{HIN}_{\mathrm{I}}$ grave e síndrome do desconforto respiratório agudo. Am J. Respir. Crit. Care Med., [s.1.]. v. 183, n. 9, p. 1200-1206, 2011.

CAGNAZZO, Túlio di Orlandi. Covid - I9: Cuidados farmacêuticos durante a pandemia. Revista Brasileira Multidisciplinar, [s. l.], v. 23, n. I, p. I6I-I78, jan./abr. 202I. Disponível em: https://www.revistarebram.com/index.php/revistauniara/article/view/973https://www. scielosp.org/article/ress/2020.v29n3/e2020233/. I2 de jan. 2020

CARESTIATO, Tatiana; WEID, Irene Von Der. REMDESIVIR: Mecanismo de ação, ensaios clínicos e pedidos de patentes depositados no INPI. MINISTÉRIO DA ECONOMIA INSTITUTO NACIONAL DA PROPRIEDADE INDUSTRIAL. Brasil, 2020. Disponível em: $<$ https://www.gov.br/inpi/pt-br/servicos/patentes/tecnologias-paracovid-19/Arquivos\%2oTextos/Estudo3_Remdesivir.pdf>. Último acesso em: Io de setembro de 2021;

CONSELHO FEDERAL DE FARMÁCIA (CFF). Levantamento mostra como o medo da Covid-19 impactou venda de medicamentos. Disponível em: https://www.cff.org.br/noticia.php.Acesso em: 20 de setembro de 2021.

DA SILVA NETO, Irineu Ferreira et al. Alvos Moleculares dos Fármacos no Tratamento da COVID-19. Cadernos de Prospecção, v. 13, n. 5, p. I251, 2020. Juazeiro do Norte, Ceará Br. Doi: http://dx.doi.org/10.977I/cp.vi3i5.3806r;

DE-CARLO, Marysia Mara Rodrigues do Prado et al. Diretrizes para a assistência da terapia ocupacional na pandemia da COVID-19 e perspectivas pós-pandemia. 2020.

DE MARGERIE, Victoire et al. Continuous manufacture of hydroxychloroquine sulfate drug products via hot melt extrusion technology to meet increased demand during a global pandemic: From bench to pilot scale. International journal of pharmaceutics, v. 605, p. I20818, 2021.

DIAS, V. M. C. H. et al. Orientações sobre diagnóstico, tratamento e isolamento de pacientes com COVID-I9. J Infect Control,[s.l.]. v. 9, n. 2, p. 56-75, 2020.

DIAZ, E. et al. Terapia com corticosteroides em pacientes com pneumonia viral primária

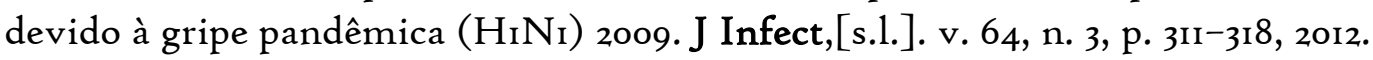

FALAVIGNA, Maicon et al . Diretrizes para o tratamento farmacológico da COVID-19. Consenso da Associação de Medicina Intensiva Brasileira, da Sociedade Brasileira de Infectologia e da Sociedade Brasileira de Pneumologia e Tisiologia. Rev. bras. ter. intensiva, São Paulo, v. 32, n. 2, p. 166-196, Junho 2020; 
FERNANDES, Igor Cardoso et al. Utilização do Remdesivir no tratamento de pacientes infectados pelo SARS-CoV-2: uma revisão narrativa. Revista Eletrônica Acervo Saúde. Vol.13(2). 2021. Doi: https://doi.org/I0.25248/reas.e66II.2021;

GOMES, Alan Hílame Diniz et al. RISCOS DA AUTOMEDICAÇÃO NA PANDEMIA POR COVID-I9: O DILEMA ENTRE INFORMAÇÕES MIDIÁTICAS E CIENTÍfICAS. AMPLA. Projeto Gráfico e Editoração: Higor Costa de Brito, p. 40, 2020. Disponível em https://ampllaeditora.com.br/wp-content/uploads/2020/o8/eBookCiencias-da-Saude.pdf $\#$ page $=40$ Acesso em: 18 de setembro de 2021;

HOSPITAL ANCHIETA. Uso indiscriminado de remédio sem eficácia comprovada contra a Covid-ı́ pode causar problemas sérios de saúde. Taguatinga - Brasília. 2020. Disponível em:< https://www.hospitalanchieta.com.br/ivermectina-e-hepatitemedicamentosa/>. Último acesso em: 20 de setembro de 2021;

IMOTO, Aline Mizusaki et al. Cloroquina e Hidroxicloroquina no tratamento da COVID-rg: Sumário de Evidências. Com. Ciências Saúde - CCS, 2020; 31 Suppl I:17-30;

JIANG, Shibo et al. Um nome distinto é necessário para o novo coronavírus. The Lancet , v. 395, n. 10228, pág. 949, 2020.

KANDEEL, M.; ELGAZAR, W.; KITADE, Y. As interações de ligação do macrolídeo endectocida ivermectina com os antibióticos ampicilina, cloranfenicol e tetraciclina HCL. Indian J. Pharm. Sci [s.1.]., v. 74, n. 6, p. 592-596, 2012. doi: 10.4103/0250-474X.110635.

MA, Qinhai et al. Liu Shen capsule shows antiviral and anti-inflammatory abilities against novel coronavirus SARS-CoV-2 via suppression of NF- $\mathrm{KB}$ signaling pathway. Pharmacological research, v. 158, p. 104850, 2020.

MARRA, Lays Pires et al. Ivermectina para covid-rg. Revisão sistemática rápida. OXFORD/BRAZIL. São Paulo, 2020. Disponível em:< https://oxfordbrazilebm.com/index.php/2020/o5/o7/ivermectina-para-otratamento-depacientes-com-covid-ı-revisao-sistematica-rapida2/ >. Último acessado em: II de setembro de 2021;

MEYER, Christian G. The COVID-19 epidemic. T [s. 1.], v. 25, n. 3, p. 278-28o, mar. 2020. Disponível em: 15 mar.2020

MINAYO, Maria Cecília de Souza. O desafio do conhecimento: pesquisa qualitativa em saúde. 8. ed. São Paulo: HUCITEC, 2004.

OLIVEIRA, H. S. B; CORRADI, M. L. G. Aspectos farmacológicos do idoso: uma revisão integrativa de literatura. Revista de Medicina, v. 97, n. 2, p. 165-176, 2018.

PINTO, A. F. D. A. Critérios de cuidados individuais e coletivos nas drogarias em tempo de COVID-19.Gestão e Tecnologia Faculdade Delta, v. I, n. 30, p.6-9, 2020. 
ROCHA, A. S.; GIOTTO, A. C. A Importância da Assistência Farmacêutica em Home Care. Revista de Iniciação Cientifica e Extenção: Revisão de Literatura, v.3, n.I, p.39o-40o, 2020.

ROCHA, Arlete Sousa; GIOTTO, Ani Cátia. A Importância da Assistência Farmacêutica em Home Care. Revista de Iniciação Científica e Extensão, v. 3, n. I, p. 390-400, 2020.

SADIO, AJ, Gbeasor-Komlanvi, FA, Konu, RY et al. Avaliação das práticas de automedicação no contexto do surto de COVID-19 no Togo. BMC Public Health 21, 58. 2021. https://doi.org/I0.I186/s12889-020-I0145-I;

SANTOS, D.; SANTOS, J. N. As Farmácias Comunitárias na Pandemia COVID-ı: Alianças Estratégicas em Contexto de Incerteza. Revista Portuguesa de Farmacoterapia, v. I2, n.I-2, p. 53-55, 2020.

SANTOS-PINTO, Cláudia Du Bocage; MIRANDA, Elaine Silva; OSORIO-DECASTRO, Claudia Garcia Serpa. O "kit-covid" e o Programa Farmácia Popular do Brasil. Caderno de Saúde Pública, v. 37, n. 2, p. 2-5, 2021. Disponível em: https://www.scielosp.org/article/csp/2021.v37n2/e00348020/. [s.1.].

SHARMA, Pallavi et al. Saponins: Extraction, Bio-medicinal Properties and Way Forward to Anti-Viral Representatives. Food and Chemical Toxicology, p. II2075, 202I.

SILVA, L. M. C. D.; ARAUJO, J. L. Atuação do Farmacêutico clínico e comunitário frente a pandemia da COVID-19. Research, Society and Development,v. 9, n.7, p.I-I4, 2020.

SMAIL, Shukur Wasman et al. Inflammation, immunity and potential target therapy of SARS-COV-2: a total scale analysis review. Food and Chemical Toxicology, p. II2087, 202I.

STACHULSKI, A. V. et al. Derivados de nitazoxanida de segunda geração: os tiazolídeos são inibidores eficazes do vírus influenza A. Química medicinal do futuro, s.1.]. v. Io, p. 851862, 2018.

VOSGERAU, Dilmeire Sant'Anna Ramos; ROMANOWSKI, Joana Paulin. Estudos de revisão: implicações conceituais e metodológicas. Revista diálogo educacional, v. I4, n. 4I, p. 165-189, 2014.

WHO DIRECTOR- General's opening remarks at the media briefing on COVID-I9 - II March 2020. Word Health Organization, [s. 1.], in mar.2020. Disponível em: https://www.who.int/director-general/speeches/detail/who-director-general-s-openingremarks-at-the-media-briefing-on-covid-I9---II-march-2020. [s.1.].

XAVIER, Analucia R. COVID-ı: manifestações clínicas e laboratoriais na infecção pelo novo coronavírus. J Bras Patol Med Lab, [s. l.], v. 56, p. I-9, 2020. Disponível em: https://cdn.publisher.gni.link/jbpml.org.br/pdf/pt_v56aoo49.pdf. Io mar. 2020 